\title{
Los símbolos y motivos en la antigua lírica popular hispánica: hacia la construcción de un diccionario
}

\section{Symbols and Motifs in Old Spanish Popular Lyrical Poetry: towards the construction of a Dictionary}

\author{
Mariana MASERA \\ (UDIR, UNAM) \\ marianamasera@yahoo.com.mx \\ ORCID ID: 0000-0002-5092-1292
}

\begin{abstract}
Symbols occurring in Spanish popular RESUMEN: El uso de símbolos en la lírica popular poetry are found in all cultures, traditions and hispánica ha sido constante en todas las culturas, historical ages. Their meaning depend on their own tradiciones y épocas históricas; pero los símbolos contexts in order to be decodified. Sometimes, they dependen de sus propios contextos para que los may even present erotic connotation. Thus, a usuarios los puedan decodificar. Muchas veces dictionary of symbols pave the way to organize a tienen significados variados, dependiendo del framework of the aspects, uses and meanings that entorno en que se presenten y, en algunas ocasiones, symbols have, and have had, over the years. In other incluso tienen connotaciones eróticas. Proponer un words, a dictionary its an important contribution to diccionario de símbolos no es tarea fácil, pero podrá understand traditional poetry in its own terms. contribuir en la construcción de un paisaje de las vertientes, usos y significados que estos tienen y han tenido a lo largo del tiempo.
\end{abstract}

KEYWORDS: Symbol, motif, tradition, poetry, song PALABRAS-CLAVE: símbolo, motivo, tradición, lírica, canción

La literatura entrelaza en una trabazón férrea lo imaginario y lo existente; transforma lo existente en imaginario y lo imaginario en existente

(Saer)

Hilo d'oro mana

la fontana,

hilo d'oro mana.

$(N C 3)$

El cancionero de la antigua lírica popular hispánica registrado durante los siglos $\mathrm{XV}$ a XVII es un crisol de muy diversas composiciones que comparten como rasgos principales «el no ser narrativas», la «brevedad», una importante presencia de la voz femenina y el marcado uso de símbolos ${ }^{1}$. La definición, aunque general, nos permite tener

\footnotetext{
${ }^{1}$ El término de lírica que utilizo sigue al expuesto por Margit Frenk en su gran antología y es el que «se refiere justo al carácter básicamente no narrativo de los materiales antologados. Muchos de ellos no son líricos en el sentido de «expresión poética de vivencias personales», y ni siquiera necesariamente en el de poesía cantada. Siguiendo un uso común de la palabra, poesía se contrapone aquí a épica y dramática (2003: 2, n. 1).
} 
un conjunto numeroso de cancioncitas que vislumbra el encuentro de varias escuelas poéticas y donde confluyen distintas tradiciones que nutren un imaginario común al pasar de los siglos ${ }^{2}$. Un ejemplo de ello es la cancioncita con estribillo y glosa de tipo tradicional recogida por Juan Vázquez en su Recopilación de sonetos y villancicos a quatro y a cinco (Sevilla, 1560) incluida por Margit Frenk en su gran antología ${ }^{3}$ :

No tengo cabellos, madre, mas tengo bonico donayre.

No tengo cabellos, madre, que me lleguen a la cinta, mas tengo bonico donayre, con que mato a quien me mira. Mato a quien me mira, madre, con mi bonico donayre. (NC 124)

Una de las principales características de la poesía tradicional es que vive variantes. De esta manera, la versión aceptada por los usuarios pasa al acervo colectivo, donde se conserva por medio de la transmisión oral, principalmente, de generación en generación a través de los siglos (Menéndez Pidal, 1960: 296-298) ${ }^{4}$. De hecho, la creación y recreación de los poemas se realiza dentro de una tradición poético musical específica, compartida por la colectividad:

un caudal limitado de tipos melódicos y rítmicos, de temas y motivos literarios, de recursos métricos y procedimientos estilísticos (caudal limitado, pero no necesariamente reducido). Dentro de él debe moverse el autor de cada nueva canción para que esta pueda divulgarse; dentro de él, también los innumerables individuos que, con el correr del tiempo, la retocan y transforman (Frenk, 1971: 11).

\footnotetext{
${ }^{2}$ Entiendo aquí imaginario como «un conjunto de producciones, mentales o materializadas en obras, a partir de imágenes visuales (cuadro, dibujo, fotografía) y lingüísticas (metáfora, símbolo, relato), que forman conjuntos coherentes y dinámicos que conciernen a una función simbólica en el sentido de una articulación de sentidos propios y figurados» (Wunenburger, 2008: 15). El símbolo de acuerdo con Helena Beristáin «es la única clase de signos que se basan por definición, en una convención [...] El objeto designado por el símbolo es siempre general, es un tipo de objeto y no un objeto individual; el símbolo no lo reproduce. El símbolo es el signo más perfecto para Pierce, porque en él se realizan los caracteres icónico, indicativo y simbólico. Jakobson retoma esta idea y concluye que todos los signos verbales son símbolos por su convencionalidad y porque tienen elementos icónicos e indiciales» (Beristain, Diccionario de poética, s.v. símbolo, p. 459) para Saussure «el símbolo, en cambio, es lo no arbitrario, pues siempre es motivado porque existe algún vínculo natural ente sus aspectos: la cruz simboliza el cristianismo; la paloma simboliza la paz, por ejemplo» (Beristain, Diccionario de poética, s.v. símbolo, p. 459).

3 Todos los ejemplos a partir de ahora serán tomados de la antología de Margit Frenk (2003), que a partir de ahora designaré como $N C$.

${ }^{4}$ Asimismo conviene repasar las acertadas acepciones que dio José Manuel Pedrosa sobre los diferentes definiciones de cancionero donde «1) Cancionero tradicional: es el absolutamente folclorizado, anónimo y «vivo en variantes»; 2) Cancionero oral: englobaría al tradicional, pero también a otro tipo de cancionero más culto, escasamente variable, de autor conocido y englobaría al tradicional y a cualquier otra forma poética cantada (culta o no, de autor conocido o no, no épico-romancística, que llegase a adquirir algún tipo de difusión, de aceptación o de proyección, tanto en el nivel de la interpretación como en el de la recepción, entre el pueblo» (Pedrosa, 2002b: 1067). En mi opinión considero equivalente para la antigua lírica hispánica los términos «popular y tradicional», como lo hace Margit Frenk (2003, 2, n. 1) también.
} 
La versatilidad y la migratoriedad de los textos es explícita, ya que la misma canción puede adaptarse en diferentes regiones para diversas funciones, $\mathrm{y}$, como consecuencia, tiene también nombres distintos, aunque preserve el mismo núcleo textual. Dicho de otra manera, y con la terminología de Sergio Baldi (1946), las variaciones realizadas en cada región serían producto de las diferentes escuelas poéticas.

La variabilidad en los cantares líricos también afecta a la métrica, es decir, una misma canción puede tener versiones en cuartetas, sextillas octosilábicas o en seguidillas, según la preferencia regional. Además, la breve extensión de los textos obliga a una economía de la palabra que autores como Stephen Reckert denominaron lyra minima, una poética compleja, donde cada término independientemente de su posición sintáctica adquiere una funcionalidad semántica, tanto denotativa como connotativa simultáneamente, permitiéndole ganar al poema una mayor densidad poética (Reckert, 1993: 37). No hay una sola palabra que no sea parte del artefacto poético, cada una aporta y amplía la sustancialidad del poema; a ello se suma el uso de símbolos como un recurso poético de gran eficacia. Sin pretender en este trabajo agotar las definiciones de estos, se torna necesario, por el gran uso del vocablo y por su gran polisemia, atender al significado expuesto por algunos estudiosos. La palabra símbolo, de acuerdo con Gadamer, significa:

«tablilla de recuerdo». El anfitrión le regalaba a su huésped la llamada tessera hospitalis; rompía una tablilla en dos, conservando una mitad para sí y regalándole la otra al huésped para que, si al cabo de treinta o cincuenta años vuelve a la casa un descendiente de ese huésped, puedan reconocerse mutuamente juntando los dos pedazos. Una especie de pasaporte en la época antigua; tal es el sentido técnico originario de símbolo. Algo con lo cual se reconoce a un antiguo conocido (Gadamer, 1991: 39).

El autor afirma que «lo simbólico en la obra de arte no solo remite al significado, sino que lo hace estar presente: representa el significado» (Gadamer, 1991: 42), no en el sentido de sustitución, sino de presencia. En sus palabras, «representación no quiere decir que algo esté ahí en lugar de otra cosa, de un modo impropio e indirecto, como si de un sustituto o de un sucedáneo se tratase. Antes bien, lo representado está ello mismo ahí y tal como puede estar ahí en absoluto» (Gadamer, 1991: 42).

Por su parte Bowra, en su trabajo sobre el origen de la poesía y la canción, señala que los símbolos expresan la naturaleza esencial de algo que de otra manera está más allá de las palabras descriptivas ordinarias, que no pueden trasmitir esa individualidad única. Agrega la capacidad de estos símbolos para iluminar el texto, relacionándolo con algo mucho más amplio y al que de alguna manera pertenece (cf. Bowra, 1984: 263).

Años después, Paul Ricoeur señala el excedente de sentido en los símbolos y afirma que su análisis se debe basar más que en la «sustitución» — como señala la antigua retórica- en la «tensión», entre dos interpretaciones, como lo hizo para definir a la metáfora. De acuerdo con el estudioso:

solo para una interpretación hay dos niveles de significación, ya que es el reconocimiento del sentido literal lo que nos permite ver que un símbolo todavía contiene más sentido. Este excedente de sentido es el residuo de la interpretación literal. Sin embargo, para aquel que participa del sentido simbólico, realmente no hay dos sentidos, uno literal y el otro simbólico, sino más bien un solo movimiento, que los transfiere de un nivel al otro y lo asimila a la segunda significación por medio del literal (Ricoeur, 1995: 68). 
Los símbolos que aparecen en las antiguas cancioncitas - me refiero a la poesía breve no narrativa - provienen sobre todo de la naturaleza y se identifican principalmente con la sexualidad humana. Muchos de estos símbolos arcaicos provienen de antiguos mitos asociados con la renovación de la naturaleza, cuya función primordial era la preservación de la vida de acuerdo con Morales Blouin (1981) $)^{5}$.

La presencia del simbolismo en la antigua lírica popular hispánica se considera como un rasgo diferenciador del estilo popular como ha sido señalado por Margit Frenk:

Uno de los rasgos a mi ver más notables de la cultura popular es el simbolismo. Me refiero a un conjunto de símbolos arcaicos a través de los cuales la naturaleza, los elementos, las plantas, los animales se identifican con la vida sexual humana. Es raro que símbolos naturales de este tipo aparezcan en la poesía culta medieval y renacentista y, cuando aparecen, son más bien tópicos estereotipados (como el Natureingang de la poesía trovadoresca) (2006: 329).

Los símbolos que aparecen en estas cancioncitas son constantes y colectivos dado que pertenecen a una tradición (Reckert, 1970: 32); la repetición de estos no es fortuita, por el contrario, el corpus de símbolos que aparece en ellas constituye un lenguaje, un código que debe ser entendido y compartido por los usuarios de esa tradición y cultura. De ahí que para la comprensión del simbolismo que prevalece en el cancionero sea necesario conocer, además de la dimensión poética del lenguaje, los mitos y ritos a los que se refieren, es decir, comprender los significados que enriquecen e iluminan a los textos ${ }^{6}$.

La antigua lírica hispánica, como toda poesía tradicional, no se comprende sin atender a la intertextualidad y al contexto (Dorra, 1981: 58), ya que la comprensión del vínculo del poema con la tradición permite conocer su significado integral. Muchos estudiosos han comentado sobre el fragmentarismo poético de estas canciones. Uno de ellos ha sido Arthur Hatto, al señalar que, a pesar de que el lenguaje poético es muy concreto, a veces se pueden observar a través del tiempo y el espacio paralelismos que pueden servir para iluminar un texto poético con otro (Hatto 1965: 65). Esto mismo se ha demostrado en la tradición hispánica, donde una canción contemporánea puede ayudar a comprender textos que de otra manera parecen crípticos.

Los símbolos recurrentes, en las diferentes culturas distantes geográficamente y a través de largos intervalos de tiempo, han preocupado a los estudiosos. Entre ellos se pueden distinguir dos grandes propuestas, como es la poligénesis que sugiere la existencia de arquetipos (Hatto, 1965: 65; Reckert, 1970, 1993, 2001), y la monogénesis que señala un origen común en un pasado remoto (Deyermond 1979-80; Frenk 1993 y Pedrosa). A lo largo de las décadas y con los nuevos aportes de la literatura comparada, la historia y la antropología culturales se propone la perspectiva de un origen común como la más adecuada para una interpretación de las manifestaciones literarias de una cultura.

\footnotetext{
5 Y también con lo que dice Hatto «Symbols are supplied by nature, by ritual and by social convention, but also are constrained by prosody and rhyme» (1965: 773).

${ }^{6}$ Frenk 1998. Maurice Bowra describe de manera acertada la relación entre los símbolos y los mitos:

«Los símbolos tienen una relación especial con los mitos. Un mito puede llegar a considerarse como un símbolo único, largo y coherente, en el que cada detalle está elaborado para alcanzar un objetivo determinado; pero, así como ciertos mitos no son simbólicos, sino históricos, del mismo modo es probable que los símbolos no hagan más que subrayar y ampliar ciertos elementos de los ritos atrayendo la atención sobre su significado» (1984: 263).
} 
Los símbolos que aparecen en las cancioncitas provienen de múltiples fuentes de la amplia tradición hispánica y, como consecuencia, son transgenéricos. Son compartidos con otros géneros - como el romancero, los cuentos- que surgen dentro de un mismo contexto cultural de producción, como lo ha demostrado a lo largo de sus trabajos comparatistas sobre la tradición panhispánica el estudioso José Manuel Pedrosa, entre otros estudiosos.

Los trabajos sobre símbolos en la antigua lírica han ido en aumento en las últimas décadas del siglo XX y principio del siglo XXI y los resultados obtenidos han allanado el camino para nuevas propuestas de investigación. Entre ellos hay aportaciones fundamentales de reconocidos estudiosos provenientes desde mediados del siglo XX hasta la actualidad. Sin pretender ser exhaustiva, sino con la intención de repasar los trabajos que han tratado este tema en particular menciono: Eugenio Asensio (1957), Arthur Hatto (1965), Eduardo Martínez Torner (1966), Mendez Ferrín (1966), Reckert y Helder Macedo (1976), John Cummins (1977), Alan Deyermond (1979-80, 2016), Egla Morales Blouin (1981) Vicente Beltrán (1976, 1984, 1987), Ria Lemaire (1987), Paula Olinger (1985) Margit Frenk (1971, 1992, 2006), Danckert (1976), Stephen Reckert (1970, 1993, 2001; 1976), Pedro Piñero (2010, 2015), José Manuel Pedrosa —en muchos trabajos estudia los motivos simbólicos- (1995, 1997, 1999, 2002 a, 2005, 2006, 2007, 2009, 2011, 2012, 2013 a, b, c, 2014, 2016, 2018) y Masera (1995, 1998, 1999, 2001 a, b, 2004, 2005, 2014, 2016). Con especial interés destaco el diccionario del alemán Werner Danckert (1976) que se basa en la comparación de las tradiciones líricas.

En el cancionero, los símbolos se relacionan entre sí formando un conjunto, un sistema, donde cada símbolo explica al otro; de este modo, la tradición se torna parte fundamental para la comprensión del poema individual. Por ello, la metodología comparatista, entre tradiciones y géneros, es la que puede ser utilizada con mayor éxito, ya que nos remite primera y necesariamente a la tradición a la que pertenecen y sus realizaciones históricas en las diferentes escuelas poéticas.

A continuación, expongo un ejemplo de la metodología que utilizo en el análisis de los motivos y símbolos del antiguo cancionero con base en el Nuevo corpus de la antigua lírica popular hispánica (siglos XV-XVII) de Margit Frenk, la antología más completa de esta lírica hasta ahora.

\section{LA CANCIÓN, UN CÓDIGO POÉTICO Y FORMAS DE DECIR}

El uso de símbolos en las cancioncitas breves responde a su eficacia poética dada su amplitud semántica, y la ventaja expresiva de poder fluir de modo casi imperceptible de lo literal a lo simbólico, o viceversa, en el plano del sentido y «a veces balancearse entre los dos», creando una tensión como ha señalado Reckert (1993: 91). De ahí que el sentido poético solo puede comprenderse por aquellos quienes comparten la tradición.

La antigua lírica hispánica ha pasado por el tamiz de la escritura en su registro y, a pesar de que se ha preservado la huella de la voz, se ha transformado adoptando y adaptando nuevas formas, símbolos y motivos provenientes de otras tradiciones escritas. De esta manera, el caudal de los símbolos asociados a las funciones rituales se reunió con las aguas de los lugares comunes provenientes de los escritos. Y a causa de estos procesos de hibridación, durante el paso de los siglos, el significado de algunos símbolos se ha transformado (Masera, 1995, 2004). 
Los símbolos, especialmente de las canciones amorosas, se asocian predominantemente con la naturaleza y recuerdan el clásico locus amoenus ${ }^{7}$ —los árboles floridos, los prados verdes y las aguas que corren-. Sin embargo, estos se empapan de nuevos significados que emergen de la tradición y de la función de las composiciones, no olvidemos que se trata de una poesía donde la brevedad de la estrofa no permite el desarrollo de las descripciones. De ahí que los adjetivos son escasos y su uso, sobre todo de aquellos calificativos, están codificados, como son los ejemplos de «verdes»o «floridas» y en ocasiones como «menuda»; en tanto que las aguas de las fuentes se señalan como «frida» o «turbia» (cf. Frenk, 1998: 174). Estos adjetivos pletóricos de erotismo que permean las cancioncitas, dada su constante aparición y frecuencia, constituyen parte del lenguaje de los símbolos y sirven de marcas en las canciones para señalar su connotación simbólica:

Canas do amor, canas, canas do amor.

Polo longo de um rio canaval vi florido Canas do amor.

\section{MOTIVOS Y SÍMBOLOS ERÓTICOS}

Entre los símbolos naturales que aparecen en la antigua lírica hispánica destaca el agua por la variedad de representaciones halladas y por la frecuencia de aparición; elemento con múltiples y a veces contrarios significados, como símbolo universal de la fertilidad o como principio y fin que precede a todas las formas de la creación ${ }^{8}$. El paisaje preferido por la antigua lírica incluye todo tipo de parajes que bañan las aguas donde se producen los encuentros amorosos o las despedidas, las esperas y las penas; las aguas que acompañan los deseos de los protagonistas, como las que van de los rosedales a las riberas del río, las orillas del mar, y las corrientes de los ríos que hay que cruzar. Todos ellos espacios liminales donde los protagonistas experimentan un proceso de transformación:

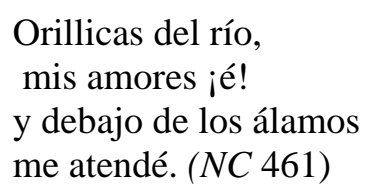

Orillicas del río, mis amores ié! y debajo de los álamos me atendé. (NC 461)

El mar, el agua salada, con las barcas y los marineros que parten se asocian con la separación de los amantes:

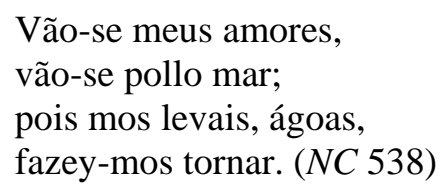

O como lugar para sufrir las penas de la malcasada:

\footnotetext{
${ }^{7}$ Véase el ya clásico trabajo sobre los tópicos de Curtius, en especial el apartado del Paisaje ideal (1995: 263-289).

${ }^{8}$ A pesar de considerar que la amplitud y universalidad del símbolo es imposible de definir, remitimos a los conocidos trabajos de Chevalier, Gheebrant (1996) y Cirlot (1992) que pueden orientar al lector.
} 


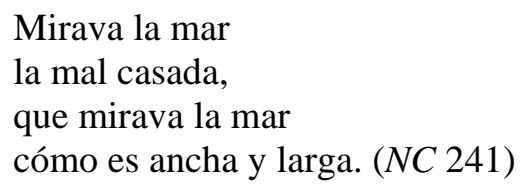

Tampoco se echan de menos las aguas dulces, donde existen corrientes de ríos cuyas orillas se estremecen con los amores de los amantes o las tranquilas aguas de la fuente, lugar idóneo para el secreto encuentro erótico como se aprecia en las siguientes cancioncitas:

En la huerta nasce la rosa: quiérome yr allá, por mirar al ru[y]señor cómo cantavá.

Por las riberas del río limones coge la virgo. Quiérome yr allá, por mirar al ruyseñor cómo cantavá.

Limones cogía la virgo para dar al su amigo. Quiérome yr allá, para ver al ruyseñor cómo cantavá.

Para dar al su amigo en un sombrero de sirgo. Quiérome yr allá, [por mirar al ruyseñor cómo cantavá]. (NC 8)

En la fuente del rosel lavan la niña y el donzel.

En la fuente de agua clara con sus manos lavan la cara. Él a ella y ella a él

[lavan la niña y el donzel]. (NC 2)

Estos símbolos acuáticos por su diversidad y frecuencia nos sirven en este artículo para indicar algunas reflexiones sobre su funcionamiento en la lírica, donde ocurren tanto las asociaciones más explícitas como aquellas más complejas, casi crípticas, que indican relaciones profundas entre las palabras y la tradición que la sostiene y las nutre ${ }^{9}$.

En las canciones tradicionales europeas, como ha sido señalado por Margit Frenk y demostrado por numerosos estudios, no hay aspecto de la naturaleza que no tenga un

\footnotetext{
${ }^{9}$ Hay todo tipo de canciones según su función social (de fiesta, de baile, rimas infantiles), donde también aparecen símbolos, sin embargo, aunque formarán parte del diccionario, no me referiré a ellas en este artículo.
} 
significado relacionado con la fertilidad y el erotismo, aunque esto no sea explícito (Frenk, 1993: 4; 2006: 331) ${ }^{10}$. Las menciones a los símbolos pluviales participan también de estos rasgos.

Uno de los métodos seguido por distintos investigadores para interpretar el simbolismo de estos cantares ha sido la comparación, primero, entre las tradiciones antiguas y las contemporáneas de una misma región. No obstante, ha resultado enriquecedor la comparación con otras culturas y otros géneros. En todos los casos donde se ha podido, se ha investigado también la relación entre el símbolo y aspectos generalmente rituales donde se alude a aquel a través de estudios de antropología y folklore.

El grupo más representativo es el de las canciones amorosas en la antigua lírica hispánica. El conjunto conforma una gran historia que se cuenta una y mil veces de distintos modos en cada uno de los poemitas; su propósito es el encuentro amoroso asociado al sentido más profundo de la vida que es la fertilidad, ya sea con resultados positivos o bien, con un sentimiento de frustración expresado de diversas formas.

En las cancioncitas de voz femenina, los símbolos se relacionan de manera muy estrecha con el personaje de la muchacha cuando aparece como locutora, esto es, como sujeto enunciador, y también en aquellas otras donde es la delocutora, es decir, el sujeto del discurso.

\section{LA FUENTE Y SUS MOTIVOS}

El personaje característico de las canciones eróticas en la antigua lírica popular es la muchacha enamorada. Sus quehaceres domésticos relacionados con lugares acuáticos como acarrear agua de la fuente, lavar la ropa o su cabello en el río, se convierten, al pasar por el tamiz poético, en símbolos de amor. El lugar pluvial elegido por la mujer se convertirá en el escenario ideal, donde se puede producir o no el encuentro amoroso y se expresa la liminalidad del personaje.

Los motivos asociados con el símbolo del agua se impregnan de erotismo y forman una red que intensifica el sentido profundamente simbólico y aumenta la densidad poética. Un ejemplo de ello puede ser el «ir por agua», donde el poder detonador de nuevos sentidos es tal que en estas canciones se ha considerado una «excusa transparente» (Gornall, 1988) del encuentro amoroso, como se aprecia en el siguiente cantar:

Enbiárame mi madre por agua a la fonte fría: vengo del amor ferida. (NC 317)

${ }^{10}$ Alan Deyermond (1989-90: 10) menciona que la situación es muy diferente en la mayoría de la lírica latina donde el paisaje se asocia con el clásico locus amoenus, de ahí que tanto los ríos como las fuentes no conllevan un sentido erótico. De acuerdo con Deyermond en la lírica latina: «Rivers may be images of mutability, of time's irreversible passing, rather than of sexual power». Asimismo, las fuentes son muy distintas a las de Pero Meogo, donde «stags come down from the mountains to stir up the water». Sobre metáfora véase Helena Beristáin: «En la metáfora no se advierte una sustitución de sentidos, sino una modificación del contenido semántico de los términos asociados» (Beristáin, s.v. metáfora, p. 309). De acuerdo con Richards: «analiza el interior de la metáfora (originada, dice, a partir de pensamientos y no de palabras), y toma en cuenta tanto la idea que se sobreentiende como la que explicita cada uno de los términos que, al asociarse, aporta semas para producir un significado excedente (un surplus) de mayor grado de complejidad y novedad del que podría expresar cada uno separadamente» (s.v. metáfora, p. 312). 
El análisis de los tres versos del estribillo sirve como muestra para comprender algunos aspectos del funcionamiento en red de los símbolos, y desglosarlos permite notar las marcas que residen en el discurso. En el primer verso, el verbo «envíarame» marca la cancioncita de manera contextual como femenina, solo aparece en esta voz (Masera, 2001), y el apóstrofe a la madre que destaca una acción obligada. En el segundo verso se completa el motivo poético con la aparición del símbolo agua y la añadidura del espacio preciso y cargado de sugerencias, la fuente; además, como si no bastara lo anterior, a este se le agrega el adjetivo fría, término que se relaciona a su vez con la fría mañana, equivalente del tópico amoroso del alba. Cierra el tercer verso ya de lleno dentro del plano simbólico con la herida de amor ${ }^{11}$.

En algunas de las cancioncitas antiguas aparece un despliegue de arsenal simbólico, como en la siguiente estrofa que sirve de glosa, donde confluyen dos símbolos destacados: por una parte, el símbolo puerta con el adjetivo intensificador «garrida» $\mathrm{y}$, por la otra, la fuente con el adjetivo «frida», al que se le añade el motivo de lavar las prendas íntimas de los amantes provenientes de la tradición gallega portuguesa.

\author{
A mi puerta la garrida \\ nasce una fonte frida \\ donde lavo la mi camisa \\ y la de aquel que yo más quería. (NC 321)
}

La suma de los símbolos, esta red que se ha formado, intensifica el significado erótico del poema y constituye así un nuevo sentido del objeto poético; sostenido por una pequeña literalidad, el poema se ha volcado a lo simbólico. Como ha señalado Ricoeur el símbolo tiene su anclaje en lo literal, pero quien lo percibe solo hay el significado simbólico (Cfr. Ricoeur, 1995: 68)

El motivo de carácter simbólico de «ir por el agua» se asocia con el cántaro roto, que aparece de un modo muy sutil en la escena donde se observa a Leonor echando lejos los pedacitos del cántaro para que no queden evidencias. $\mathrm{O}$, de otro modo, la escena muestra a la muchacha transformada irremediablemente tras el encuentro amoroso:

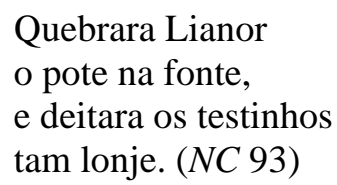

En cuanto al aspecto literal de la cancioncita, se sabe que desde la Edad Media una de las labores domésticas de las mujeres era ir por agua a la fuente. En el aspecto

\footnotetext{
${ }^{11}$ La preservación de la fuente como lugar del encuentro de los amantes pervive hasta los cancioneros del siglo XX, tanto en voz femenina como en masculina. Por ejemplo: «Dile que no voy, que no voy, que no vaya; / dile que no voy a la fuente por agua; / dile que no voy, porque estoy enamorada» Córdova y Oña 1948-55: III, 79, n. ${ }^{\circ}$ 46; Torner 1920: n. ${ }^{\circ}$ 270. Sin embargo, cuando aparece en voz masculina, en los cancioneros actuales se añade el motivo de «mirar al agua» con el consecuente peligro de quedar enamorado, que se halla registrado en el motif index de Thompson asociado con el mito de Narciso: «Si vas a la Fuente, / no mires el agua, / que los tus amores / son míos zagala». En el cancionero tradicional mexicano aparece directamente la invitación del hombre a la muchacha, donde también es usado como una excusa transparente: «Si quieres, conmigo vente, / que me voy a divertir/ a la margen de una fuente, / a ver el agua salir» (CFM, 1339 [«El Balajú»]).
} 
simbólico el cántaro representa a la propia muchacha y su virginidad, como se aprecia en una tradición, un ritual, de casamiento en Castilla:

después de acordado la noche para concertar el día de la boda, el padre y padrino visten sus mejores galas y van a la casa de la novia «quienes reciben a los visitantes y les hacen sentar alrededor de una mesa pequeña con un mantel blanco, sobre la cual ponen una torta de pan, un cuchillo y una jarra colocada boca abajo; si la novia no fuese virgen la jarra ha de ser vieja y rota» [después que se hizo el arreglo] «el padre de la novia anuncia el concierto volviendo boca arriba la jarra y llamando a la novia para que eche vino» (Jambrina Real, González Matellán, \& Madrid Martín 1986: 304-05).

Los motivos también fueron estudiados por Alan Deyermond, quien señala que en esta lírica «the fountain represents life-giving sexuality, the broken pitcher (like torn or stained garments) stands for a broken maidenhead» (1979-80: 266). La escena y sus motivos están presentes en las tradiciones actuales de España y en cada región se añaden o varían elementos, como resultado de la adopción y adaptación que hacen los usuarios de la tradición, como se aprecia en el siguiente cantar:

Minha mãe mandoume à fonte-,

pela hora do calor,

eu rachei a cantarinha,

a falar com o meu amor ${ }^{12}$.

En el cantar anterior está el motivo de la muchacha rebelde que, a pesar de que la madre la envía por agua, y se añade como intensificador primero «a la hora del calor», ella ha ido a ver a su amante, como queda claro cuando expresa que ha «roto el cantarito al hablar con su amor». Con esta última línea se resignifica la estrofa y la ruptura del cantarito cobra su dimensión simbólica. En este mismo sentido podemos estudiar la siguiente cancioncita donde es la madre la que revela la excusa transparente:

\author{
Minha filha foi à fonte \\ moito tarda que non ven; \\ ou quebroull'o cantariño \\ ou um rapaz a detem. (Crespo 1966: 195)
}

Las canciones contemporáneas han ayudado a comprender el sentido de las antiguas. De esa manera, cuando escuchamos el siguiente estribillo la lectura será diferente porque se entiende que el cantarito nuevo se refiere a la sexualidad de la muchacha:

Pois o cantarico hé novo, quero ir, mana, comvosco. (NC 467)

12 Mourinho (1984: 145, n. $\left.{ }^{\circ} 45\right)$. Para las versiones gallegas véanse: Rielo Carballo (1980: 25, n. ${ }^{\circ}$ 42); Rico Verea (1988: 67, n. ${ }^{\circ} 3$ ). El tema de quebrar o romper el cántaro es muy en el cancionero panhispánico. Alsgunos ejemplos de versions gallegas puede ser señalada la siguiente copla que aparece en una canción infantil «As pombinhas da Catrina»: «Minha mãe mandou-me à fonte / E eu parti a cantarinha, / Minha mãe mandou-me à fonte / E eu parti a cantarinha. // - Ó minha mãe não me bata / Que eu ainda sou pequenina! / —ó minha mãe não me bata, / Que eu ainda sou pequenina!» («Os cantinho das crianças»): <https://sites.google.com/site/ocantinhodasbrincadeiras/cancoes/as-pombinhas-da-catrina-1〉). 
Otro motivo asociado al agua —el «miedo al agua»— puede ser tanto a la salada como la del mar, o dulce como la del río. Egla Morales Blouin señala que el miedo se puede interpretar no solo como temor hacia el acto sexual, sino también como el terror que existe en mitos acuáticos y los sacrificios hechos a los dioses del agua (1981: 65-67). Los motivos que aparecen en las cancioncitas son «el miedo de cruzar el agua» y el miedo «de ser llevada por el agua».

¿Por qué existe el miedo a cruzar? En las diferentes mitologías indoeuropeas la acción de cruzar el río representa el paso al inframundo. Basta recordar los nombres de las aguas Estigia, Acheron o Cocytus sobre las que Caronte navega con su barca llena de las sombras de la muerte. En tanto que, en los mitos celtas y alemanes, el río que hay que atravesar para pasar al otro mundo tiene aguas torrenciales ${ }^{13}$. Dentro de la antigua lírica, sin embargo, el simbolismo de amenaza ante un cambio o una transformación por parte de la protagonista se asocia con los que Arnold Van Gennep ha denominado un rito de pasaje, que comprende «all ceremonial patterns whic accompany a passage from one situation to another or from one cosmic or social world to another» (2004: 10).

En la hermosa cancioncita que aparece en el pliego suelto del siglo XVI titulado Cantares de diversas sonadas con sus deshechas muy graciosas ansí para baylar como para tañer, y que encabeza una glosa, dado que aparece el símbolo de la puerta que marca contextualmente el discurso en voz femenina, se escucha una voz que dice tener miedo de salir de su casa porque «hay una fuente y no quiere mojarse»:

A mi puerta nasce una fonte:

¿por dó saliré que no me moje? (NC 321)

La conjunción de símbolos con tanta fuerza poética como la puerta y la fuente en el primer verso enfatizan el erotismo de la pregunta de la protagonista. El miedo de la muchacha a punto de atravesar el umbral de su casa es en su modo simbólico, el de la transformación de su cuerpo ${ }^{14}$. El ejemplo se relaciona con otra cancioncita donde se aprecia una situación similar que le acontece a una muchacha en Sevilla, pero ahora su temor es cruzar el río pues puede mojarse los zapatos:

¡Río de Sevilla,

quién te passasse

sin que la mi servilla

se me mojasse! (NC $2352 \mathrm{~A})^{15}$

${ }^{13}$ Grimal (2008: s.v. Caronte). Graves (1960: I, n. ${ }^{\circ}$ 31). En otras mitologías (clásica, celta y germánica) el río es descrito como peligroso y de aguas torrenciales (cf. Patch, 1956). El motivo de cruzar el río como puerta a otro mundo aparece en las baladas escocesas e irlandesas (Wimberly, 1928: 108-120). Para la transformación causada por cruzar el río o las aguas, véase también en Thompson (1955-58: D574).

${ }^{14}$ Sobre esta canción y sus significados simbólicos véanse: Frenk (2003), Masera (2001, 2004).

${ }^{15} \mathrm{El}$ simbolismo erótico de los zapatos es de muy larga tradición. En esta canción aparece la «servilla» «es un calzado de unas çapatillas, de una suela muy a propósito para las moças de servicio; y assí tomaron el nombre de siervas, o de las que sirven, porque las demás que no han de andar con tanta desenvoltura traen chapines» (Covarrubias, 1611: s.v. servillas, 935b and chapín 432 b). El significado de «Ya en servilla, ya en chapín» es equivalente a «ya en moza, ya en dama» Alzieu, Jammes \& Lissorgues (1975: 132, n. 10). Véase Thompson (1955-58): usar zapatos solo para cruzar el río F1015.2; y véase como tabú pasar el río con un pie seco C833.5. Asimismo, véase la amplia bibliografía de los artículos de José Manuel Pedrosa $(2007,2013 \mathrm{a})$, donde señala la relación de romper o mojar los zapatos con las connotaciones sexuales tanto en canciones como en géneros narrativos. 
Por una parte, el cruzar el agua es un símbolo del encuentro amoroso de acuerdo con Morales Blouin, en tanto que entre los cantos tradicionales rusos el cruzar el agua es un símbolo muy común para el matrimonio (Sokolov, 1971: 522). A ello se suma que cruzar el río es un símbolo ritual cargado de erotismos y asociado a la renovación del vigor sexual, como también es señalado por Monique De Lope cuando analiza el episodio de las serranas en el Libro del Buen Amor:

Passer le ruisseau est donc un symbole rituel chargé d'érotisme, lié au renouvellement de la vigueur sexuelle, à l'affirmation du coit et à la promesse de la fécondité. Ce niveau érotique de l'eau rituelle est manifestement inscrit dans cet épisode du Libro de Buen Amor, et la «serrana» qui franchit ai si les ruisseaux avec le voyageur est même désignée, dans un des manuscrits du texte (S) par le ot novia, la Chata novia (s. 972) (De Lope, 1985: 159$)^{16}$.

En su estudio sobre las fiestas de mayo, Caro Baroja cita un ritual asociado al palo de mayo, al que un joven sube para colocar una cruz y una guirnalda de flores, mientras las casadas entonan una canción que comienza «Aquel río tan fresco que tengo que pasar» (Caro Baroja, 1979: 188) ${ }^{17}$.

Tampoco podemos dejar a un lado la posibilidad de que se aluda a la potencia sexual masculina (Hawking, 1979: 247). De todas estas acepciones podemos ver que el «cruzar el agua» representa también en el cancionero antiguo un «rito de paso», y, en especial para la muchacha, mojarse significaría su transformación sexual y social.

En la antigua lírica muchas veces la voz masculina sugiere ciertos obstáculos que impiden llegar hasta la amada que ${ }^{18}$, con el tema de cruzar el río, reclama que no hay un puente y, por ello, no puede cruzar el río que está a la puerta (véase más arriba sobre la puerta y el agua):

¿Cómo quieres que vaya

de noche a verte?

Si a tu puerta hay un río, ¡no tiene puente! $!^{19}$

${ }^{16} \mathrm{La}$ autora continúa señalando que en las imágenes del agua se realiza el encuentro entre dos tradiciones la clerical y la tradicional: «Ainsi donc, deux discours se croisent, se complètent et s'opposent, autour des images de l'eau médiatrice et médiatisée, et celles du franchissement symbolique que le texte leur associe. D'un côté un discours clérical fondé par toute la tradition chrétienne des textes qui évoquent l'eau dans son rapport à la grâce divine et au salut, à l'immortalité de l'âme. De l'autre, un discours fondé sur les éléments traditionnels d'une culture depuis longtemps dominée, et qu'on ne peut entendre qu'en le référant à des rites et des croyances que le christianisme n'a pas complètement éliminés, et qui stimulent encore l'imaginaire médiéval. Les images de l'eau sont prises dans ces deux discours: une eau non point pure et innocente, au sens ou A. Robbe-Grillet parlait de la métaphore, mais une eau qui véhicule les questions et les interprétations de l'homme sur son rapport au monde et au divin» (De Lope, 1985: 159).

${ }^{17}$ Véase también (De Lope, 1985: 159).

18 Algunas veces la condición es que amarre a su perro véase $N C 1669$ y allí la sección de correspondencias. Ambos obstáculos el río y el perro tienen en estas coplas connotaciones eróticas. Véanse: Frenk (2006: 353-372) y Masera (1995: dog).

${ }^{19}$ Schindler (1941: n. ${ }^{\circ}$ 324). Véase también García Matos (1982: 52, n. $\left.{ }^{\circ} 113\right)$. Para el significado de cruzar el puente véase también Masera (1995). 
En este caso no sabemos si sugiere que la muchacha está dudosa de entregarse o la existencia de algún obstáculo impuesto por alguien más. En las siguientes canciones el amante se convierte en el río:

Miniña tan bonitiña, o color, ¿quen che levou?

Pasáche o río de noite:

a auga te mareou. (Blanco, 1992: I, 366, n. ${ }^{\circ}$ 1060)

¿A ónde te has ido, niña?

¿A ónde te has ido a por agua a la fuente teniendo río? (García Matos, 1951-60: II, texto n. $\left.{ }^{\circ} 444\right)$

En este vaivén entre la antigua lírica y los cancioneros que se cantan o cantaban en el siglo XX, hemos señalado la connotación del río como el amante y el motivo de cruzar el río como un símbolo la transición entre el celibato y el matrimonio. Una vez comprendidos ambos motivos se ilumina el sentido de una canción de Gil Vicente:

Vayámonos ambos, amor, vayamos, vayámonos ambos.

Felipa e Rodrigo passavam o rio.

Amor, [vayamos],

vayámonos [ambos Felipa e Rodrigo] (NC 463)

En la anterior cancioncita tanto el estribillo como los dos últimos versos expresan la urgencia de irse juntos los amantes, «vayámonos ambos», expresión similar que usa la muchacha en otra canción asociada con el símbolo de la luna:

Salga la luna, el cavallero,

salga la luna, y vámonos luego.

Cavallero aventurero,

salga la luna por entero,

salga la luna, y vámonos luego.

Salga la luna, el cavallero,

salga la luna, y vámonos luego. (NC 459)

La salida de la luna, como la acción de cruzar el río, sugiere la transición de la muchacha en mujer, es decir, la muchacha está lista para el encuentro amoroso, para su transformación sexual y ella es quien urge al amado a marcharse, como lo ha señalado Frenk (1993, 2006: 329-35). Sin embargo, en las canciones modernas en la región de Galicia existe un cantar donde es explícito que pasar el río y mojarse una prenda connota la transición social, el casamiento de la muchacha: 


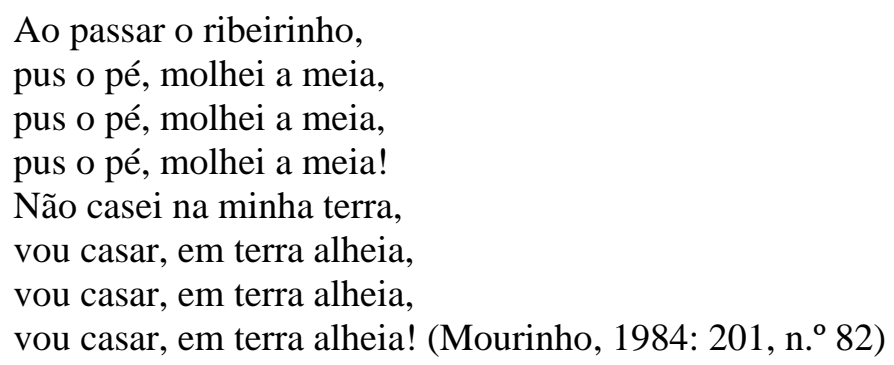

En este mismo sentido el motivo de «llevar a la muchacha del otro lado del río» sugiere el casamiento y, por ende, la transformación sexual en la siguiente copla, cuyos últimos dos versos refieren al elemento del pan de centeno y de trigo. La acción de comer pan de trigo la señala como una muchacha delicada y de clase alta:

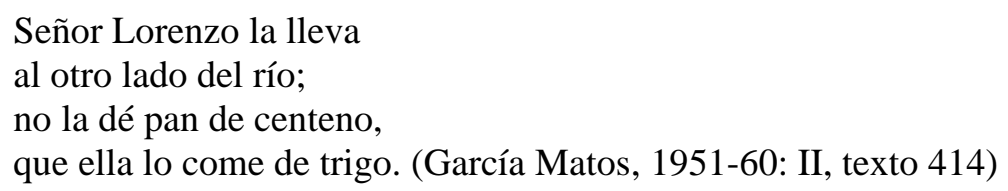

No siempre tiene un feliz resultado atravesar las aguas corrientes, como se aprecia en la siguiente cancioncita que surge como una queja de malmaridada y donde se introduce un nuevo elemento: el barco. Este se asocia con otra serie de canciones que veremos adelante:

Mal haya la barca que acá me pasó, que en casa de mi padre vien m'estava yo. (NC 926)

El motivo de cruzar el río en las canciones contemporáneas puede estar en voz masculina o femenina. En el siguiente cantarcito de intenso erotismo se registra una acumulación de motivos simbólicos de gran profundidad poética, y permanencia en la tradición que involucran elementos como las flores y el viento:

Tengo de pasar el río

aunque sepa de mojarme, a cojer aquella rosa que la bambolea el aire. (Cortés, 1914: n. $\left.{ }^{\circ} 4579\right)$

En este estribillo el hombre es quien atraviesa las aguas corrientes y no tiene miedo de hacerlo, a ello se suman motivos como «coger la rosa que bambolea el aire» que son acciones asociadas a la voz masculina. Sobre todo, en la lírica contemporánea, el hombre es quien coge la flor, la corta, y a ello se suma que el viento es un elemento asociado a la masculinidad, el que la sacude (cf. Masera, 1995: the wind). De esta manera, el pasar las aguas no remite a una transición de un estatus social del protagonista, sino más bien al deseo de la consumación del deseo erótico.

La transformación derivada de la acción de cruzar el río sería pues significativa tanto para el hombre como para la mujer en la lírica contemporánea, en tanto que en la antigua aparece de manera más contundente en la voz femenina al menos en los registros conservados. Como ha señalado Morales Blouin: 
aunque no tuviésemos información alguna sobre los mitos y los rituales en los que se arraigan las costumbres que ligan el amor con el agua, el mar y los barcos [...] debe tenerse constantemente en cuenta que lo que más tarde se vuelve adorno y retórica en la canción culta, tiene en lo tradicional vigente veracidad de un pensamiento más arcaico que se enraíza profundamente en la inseparabilidad del agua con la fecundidad (1981: 107).

La red de símbolos se completa con elementos propios del campo semántico como el remador y el barquero, también de connotaciones eróticas en la antigua lírica, quienes son capaces de cruzar el mar y de allegar el barco a la rivera, de hacer posible el deseo de la muchacha que no puede atravesarla sola:

En llegando a la barca

dixe al barquero

que me pase el rrío,

que tengo miedo. (NC 947)

Sin embargo, en otra ocasión, puede ser el barquero sustituido por el «morico»:

Allega, morico, allega,

con el varco a la ribera. (NC 946)

El deseo de la niña se refleja en la intensidad de su petición para que atraque el barquero el barco, esta es «la contrafigura de la mujer junto al agua para el varón» (Blouin, 1981: 107). El barquero ya no aparece en la lírica contemporánea de las costas, sino que es el marinero, una actualización del vocablo en la ejecución, al que la niña enamorada le suplica que atraque la embarcación:

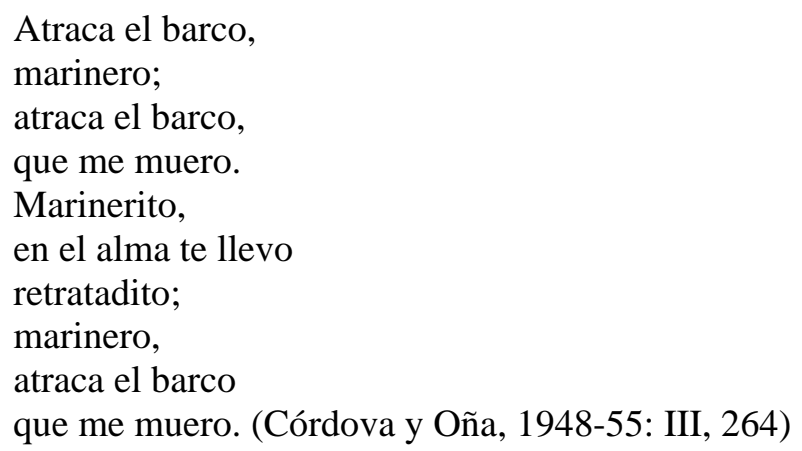

La misma súplica se escucha en otro cantar a un personaje masculino, quien también ordena al marinero orillar el barco para cumplir su ardiente deseo, expresado en las palabras «que esta noche no duerme sola la niña» $\mathrm{y}$ «orilla el barco que me muero»:

Orilla, orilla,

que esta noche no duerme

orilla, orilla,

que esta noche no duerme

sola la niña, marinero,

orilla el barco que me muero. (Torner, 1920: n. ${ }^{\circ} 304$ ) 
A lo largo del apartado se revela, a través de las canciones con símbolos y motivos asociados al agua, la complejidad poética que emerge de la antigua lírica popular y del cancionero tradicional, así como la necesidad de descifrarlos en su amplio contexto para su mejor comprensión.

HACIA UN ÍNDICE DE SÍMBOLOS, METÁFORAS, TÓPICOS, MOTIVOS E IMÁGENES DE LA ANTIGUA LÍRICA POPULAR HISPÁNICA

Espero en este breve recorrido haber demostrado la importancia de poner en diálogo a las cancioncitas tanto diacrónica como sincrónicamente entre la misma tradición hispánica como con otras tradiciones. El método elegido permite reconocer a través del contexto la estrecha relación entre los cantares y, por ende, aporta un conocimiento del sentido de muchas de ellas a través de la comparación.

Dado lo anterior, me parece muy importante hacer un índice de símbolos, motivos y tópicos de la lírica panhispánica como parte de un imaginario compartido por otros géneros, por lo que este índice o diccionario puede servir como punto de partida para un trabajo colaborativo de un gran diccionario de la tradición oral hispánica.

Un índice que, como ha señalado Heda Jason (2000: 15) sirva en primera instancia a todos los interesados en estos géneros para la localización de los textos, y que ofrezca un repertorio cultural presentado de manera sistemática donde puedan identificarse los cambios históricos en los distintos géneros.

El lenguaje de la poesía tradicional, como hemos dicho, se caracteriza por su brevedad y por el uso de recursos que son conocidos por una colectividad. De esta manera, como ha señalado Magis, «el estudio de lugares comunes en la poesía tradicional no solo resulta utilísimo, sino imprescindible» (1969: 29 ${ }^{20}$. Entre las formas estereotipadas que se encuentran en las canciones solo destacamos tres que son el tópico, el motivo y el cliché, dejando el esquema fuera de este estudio. Ordenados en cuanto al grado de estereotipia donde para Magis el motivo «es un tema menor que se estereotipia en cuanto al modo de experiencias pero que no se ha cristalizado en los medios expresivos»; en tanto que el tópico sí «es la cristalización de todo un complejo temático expresivo» (1969: 33). Finalmente, el cliché se define como «un grado de lexicalización y de estatismo más avanzado que el del tópico» (Magis, 1969: 35).

Si bien compartimos con Magis la necesidad de realizar esta categorización de las estereotipias, también diferimos en cuanto al tópico que «sería más amplio que el motivo», de hecho, estaría compuesto por una serie de motivos. Así el agua es un topoi que tiene asociado una serie de motivos como «ir por agua», «lavar la ropa», «cruzar las aguas».

Siguiendo esta línea de pensamiento y, basándome en mi trabajo anterior, una primera base de la clasificación incorporaría a los «tópicos» y los motivos asociados a las canciones. Tendríamos otra categorización donde entrarían los símbolos que están a su vez jerarquizados en tópicos y motivos con carácter simbólico. Sería el cado de los símbolos propios de la mujer como el tópico del cabello y los motivos de cortarlo, lavar y secarlo, dormir bajo la sombra de los cabellos. Es decir, el motivo sería la unidad de

20 Véase Aurelio González «En conclusión podemos decir que los motivos son unidades mínimas narrativas que conservan y expresan en la cadena sintagmática de la cual forman parte un significado que se localiza en un nivel más profundo de la narración (el plano de la fábula)» (González, 2012: 381). «El concepto de motivo: unidad narrativa en el Romancero y otros textos tradicionales» (González, 2012: 353384). También revisar «Refuncionalización de motivos folklóricos en las coplas de México», González (2012). 
contenido recurrente donde existiría la cristalización del modo de expresión y donde se involucra una acción ${ }^{21}$. Puede abarcar desde personajes como la muchacha o un allomotif, como la chica que lava sus cabellos, una marca temporal como el alba y elementos formuláicos como la «mañana de San Juan». Se estudiarán también las metáforas y las imágenes.

El repertorio de carácter digital será organizado por fichas individuales. En cada cancioncita se marcarán las palabras significativas; en muchos casos y por la brevedad del verso, cada vocablo de cada verso puede ser marcado, es decir, la connotación simbólica de cada palabra va conformando diferentes bases de datos que se relacionan:

A mi puerta nasce una fonte:

¿por dó saliré que no me moje?

De este modo, el usuario podrá entrar a la palabra fuente, allí podrá obtener una definición, pero a la vez podrá realizar el recorrido de todos los textos que contienen fuente, con sus diversos motivos. Y siguiendo el formato del Nuevo corpus, tanto en temas como en el aparato crítico, tendrá los campos de fuentes, correspondencias, estudios, entre otros.

Como se ha señalado, en este tipo de lírica no es suficiente dar una definición que quedaría muchas veces incompleta, sino que se ofrecerá la opción al usuario de recorrer varias formas de consulta que permitan una mejor comprensión del significado o significados del símbolo y de la tradición de la que emerge. Además de señalar su permanencia en las distintas tradiciones, por mencionar algunas búsquedas.

La realización de este índice con el uso de las humanidades digitales permite ofrecer nuevas formas de trabajar y de organizar los repertorios que sustentan estas investigaciones y sería un aporte a los estudios de la lírica panhispánica y europea. Un trabajo arduo sí, pero que bien vale la pena.

${ }^{21}$ Véase Jason que agrega sobre el motivo literario «we will add the quality that such unitsare contexts free and free-floating explica que el motivoIn a literary work the individual motif is put into a context and coupled with other such individual motifs. The coupling with othre motifs makes the motif function in some way and loads it with meaning. The motifs employed by a certain culture constitutes a "common pool; each folk literary genre will draw from this pool its specific assemblage of motifs and have its preferred coupling of motifs. Thus, each cukture will have its repertoir of motifs and their coupling, The pool of motifs may be universal and accesible to all cultures; however, that has not yet been demonstrated» (2000:22). En cuanto al motivo señala: «A motif acquires structural, narrative and semantic function and value in the framework of a specific text (Jason 2000: 22). The literary content of the work should be decomposed into de the following elements which we will call motifs: (1) single characters and their qualities; (2) single requisites and their qualities; (3)single deeds and their qualities; (4) typical and recurrent couplings of elements 1 to 3, including subject, action and object and thereby equaling Propp's function and Dundes "allo-motif"; (5) passive form: results of an action; (6) spatial (geographic) and temporal markas and their special qualities; (7) formulae and formulaic numbers». 
ANEXO 1. UNA PROPUESTA DE ÍNDICE REALIZADA ${ }^{22}$

TOPOI

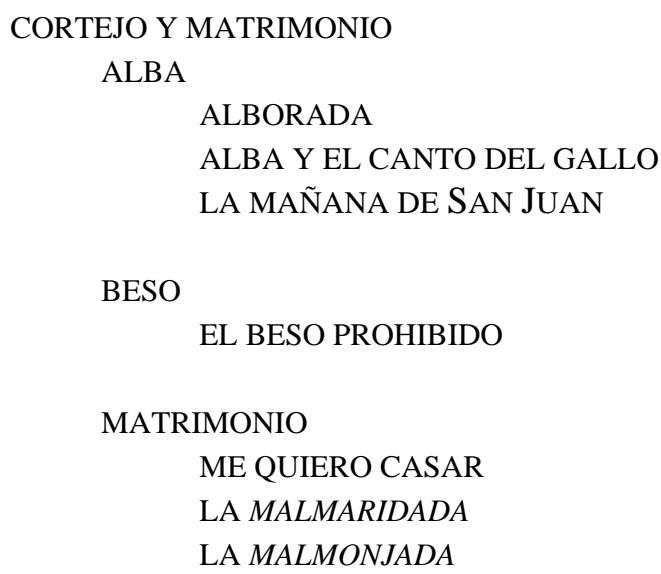

CANCIONES DE TRABAJO

CANCIONES DE TRABAJO DE MUJER:

LA HILANDERA

LA PANADERA

CANCIONES DE TRABAJO DE HOMBRES Y MUJERES

EL PASTOR

LA SIEGA

SÍMBOLOS

SÍMBOLOS NATURALES

AGUA

LA FUENTE

TRAER AGUA

EL CÁNTARO ROTO

RECOGER FLORES EN LA FUENTE

AGUAS TURBIAS

EL RÍO

LAVAR LA ROPA

LAVAR, SECAR Y TENDER

AGUAS CORRIENTES

EL MAR

EL MAR FÉRTIL

EL MIEDO AL AGUA

CRUZAR EL AGUA

SER LLEVADO POR EL AGUA

LA LLUVIA

\footnotetext{
${ }^{22}$ Este índice se propuso en el trabajo de Masera (1995).
} 
LOS ÁRBOLES

LAS FLORES Y LAS FRUTAS

EL VIENTO, LA MONTAÑA Y LA LUNA

SÍMBOLOS ANIMALES

AVES

EL PAVO Y LA PERDIZ

EL CANTO DEL GALLO

AVES QUE SIMBOLIZAN LOS GENITALES

MAMÍFEROS

EL PERRO

LA MUJER

LA MORENITA

LA MORENITA Y LA TIERRA

LA MORENITA Y EL CASAMIENTO

LA MORENITA Y SUS EXCUSAS

LA MORENITA BAJO LA SOMBRA DEL AMOR

LA MORENA COMO RESULTADO DE LA MALA SUERTE O BRUJERÍA

EL CABELLO Y LA CINTA

EL CABELLO LARGO

EL CABELLO SUELTO Y EL CABELLO CORTADO

BAJO LA SOMBRA DE LOS CABELLOS

LAVAR Y PEINAR LOS CABELLOS

LA CINTA

LA CINTA VERDE

LA CINTA ROJA

LA CINTA DE ORO

SÍMBOLOS ASOCIADOS CON LA VIRGEN

ESPACIOS

LOS ESPACIOS: LA CASA, EL CASTILLO Y EL MOLINO

EL ESPACIO PRIVADO

LA PUERTA

LA PUERTA ABIERTA

LA PUERTA ABIERTA POR LA MUCHACHA

EL HOMBRE A LA PUERTA

EL MOLINO

EL MOLINERO Y LA MOLINERA

EL CASTILLO 


\section{BIBLIOGRAFÍA}

Alzieu, Pierre, Lissorgues, Yvan \& JAMmes, Robert (ed.) (1975): Floresta de poesías eróticas del Siglo de Oro, Toulouse, France Ibérie Recherche.

ARCIPRESTE DE HitA (1988): Libro de buen amor, G. B. Gybbon-Monypenny (ed.), Madrid, Castalia.

ASENSIO, Eugenio, 1957: Poética y realidad en el cancionero peninsular de la Edad Media, Madrid, Gredos.

BALDI, Sergio (1946): «Sul concetto di poesia popolare», Leonardo, Rassegna Bibliografica (Firenze), pp. 15: 11-21, pp. 65-77.

BELTRÁn, Vicente, ed., 1976. La canción tradicional, Tarragona, Tarraco.

BELTRÁN, Vicente, 1984. “"Oh vento lh'as levava”: Don Denis y la tradición lírica peninsular», $B H, 86: 5-25$. DOI: https://doi.org/10.3406/hispa.1984.4517

Beltrán, Vicente, ed., 1987. Canción de mujer, cantiga de amigo, Textos Medievales, 8, Barcelona, PPU.

BERISTÁIN, Helena (2013): Diccionario de retórica y poética, México, Porrúa.

Blanco, Domingo (ed.) (1992): A poesía en Galicia, 2 vols, Vigo, Edicións Xerais de Galicia.

Blouin, Egla Morales, 1981. El ciervo y la fuente: mito y folklore del agua en la lírica tradicional, Potomac, MD, Studia Humanitatis.

Bowra, C. M. (1962): Primitive Song, London, Weidenfeld and Nicolson.

CARO BAROJA, Julio (1979): La estación de amor: fiestas populares de mayo a San Juan, Madrid, Taurus.

Cirlot, Juan Eduardo, (1992): Diccionario de símbolos, Barcelona, Labor.

CóRdova Y OÑA, Sixto (ed.) (1948-55): Cancionero popular de la provincia de Santander, 4 vols, Santander, Diputación Provincial.

COVARRUBias, Sebastián de (1943): Tesoro de la lengua castellana, Martín de Riquer (ed.), Barcelona, Horta.

CRESPO, Firmino, (1966): «A Tradição de uma Lírica Popular Portuguesa antes e depois dos Trovadores», Occidente (Lisboa): 71: 98-107, 121-128, 185-203.

Cummins, John G., ed., (1977): The Spanish Traditional Lyric, Oxford, Pergamon Press.

CURTIUS, Ernts R, (1995): Literatura europea y Edad Media Latina, Margit Frenk (trad.), Mexico.

CheVAlier, Jean y GHeERBRAnt, Alain (1996): Dictionnaire des symboles, Paris, Robert Laffont.

DANCKERT, Werner (1976): Symbol, Metapher, Allegorie im Lied der Völker, ed. Hannelore Vogel, 4 vols, Bonn, Verlag für Systematische Musikwissenchaft.

DE LOPE, Monique (1985): «Le Gué et l'aquéduc: l'eau et les discours du passage dans le Libro de Buen Amor», en L'Eau au Moyen Âge, Senefiance, 15, Aix-en-Provence, Université de Provence, pp. 249-58.

DeYermond, Alan (1979-80): «Pero Meogo's Stags and Fountains: Symbol and Anecdote in the Traditional Lyric», $R P h, 33$, pp. 265-83.

DEYERMOND, Alan (1989-90): «Traditional Images and Motifs in the Medieval Latin Lyric», $R P h, 43: 5-28$. 
DEYERMOND, Alan, (2016): «The Wind and the Small Rain: Traditional Images in a LateMedieval English Court Song and their Contemporary Castilian Analogues» en Claudia CARRANZA y Mariana MASERA (eds), Folklore y Literatura en la lírica panhispánica Lyra Minima I, México, UNAM, pp. 15-31.

DORRA, Raúl (1981): Los extremos del lenguaje en la poesía tradicional española: estudios sobre el villancico y la poesía gongorina, México, UNAM.

FRENK, Margit (1971): Entre folklore y literatura: lírica hispánica Antigua, México, El Colegio de México.

FRENK, Margit (1975-1998): Cancionero folklórico mexicano, 5 vols., México, El Colegio de México, Centro de Estudios Lingüísticos y Literarios.

FRENK, Margit (1993): Symbolism in Old Spanish Folk Songs, The Kate Elder Lecture, 4, London: Dept of Hispanic Studies, Queen Mary and Westfield College).

FRENK, Margit (1998): «Símbolos naturales en las viejas canciones populares hispánicas», en Lírica popular/ lírica tradicional. Lecciones en homenaje a Don Emilio García Gómez, Sevilla, Universidad de Sevilla, Fundación Machado, pp. 159-182.

FRENK, Margit (2003): Nuevo corpus de la antigua lírica popular hispánica (siglos XV a $X V I I)$, Volumen I y II, México, Facultad de Filosofía y Letras, UNAM; Colegio de México y Fondo de Cultura Económica.

FRENK, Margit (2006). Poesía popular hispánica. 44 estudios, México: FCE.

GADAMER, Hans Georg, 1991. La actualidad de lo bello, Barcelona, Paidós.

García Matos, Manuel (1951-60): Cancionero musical de la Provincia de Madrid, Juan Tomás Parés y José Romeu Figueras (ed.), 3 vols, Barcelona, Instituto Español de Musicología, CSIC.

GONZÁLEZ, Aurelio (2012): «Refuncionalización de motivos folklóricos en las coplas de México», Olivar: Revista de literatura y cultura española, 18, pp. 177-200.

GORNALL, John, 1988. «Transparent excuses in Spanish Traditional Lyric: A Motiv Overlooked?», Modern Language Notes, 103, pp. 436-439.

DOI: https://doi.org/10.2307/2905350

GRIMAL, Pierre (2008): Diccionario de mitología Griega y latina, Barcelona, Paidós.

GRAVES, Robert (1960): The Greek Myths, 2 vols., Harmondsworth, Penguin Books.

HAтTO, Arthur T. (1954): «The Lime Tree and Early German, Goliard, and English Lyric Poetry», MLR, 49, pp. 193 209. DOI: https://doi.org/10.2307/3718904

HAWKING, Jane (1979): «The Dawn: A Study of the Image and Related Themes in the Traditional Love Lyric of Medieval Spain and Portugal», unpublished doctoral thesis, Westfield College, University of London.

JAMbrina REAL, Alberto; GonZÁleZ MATELlÁn, José Manuel y MADRID MARTín, Pablo (1986): «Ritos y cantos de boda en la provincia de Zamora», en Etnología y folklore en Castilla y León, ed. Luis Díaz Viana, Estudios de Etnología y Folklore, 2, Valladolid, Junta de Castilla y León, pp. 301-333.

JASON, Heda (2000): Motiv, Type and Genre, Soumi, Soumalainen Tiedaekatemia, Academia Scientiarum Fennica.

LEMAIRE, Ria (1987): Passions et positions: contribution à une sémiotique du sujet dans la poésie lyrique médiévale en langues romanes, Amsterdam: Rodopi.

Magis, Carlos H. (1969): La lírica popular contemporánea, México, El Colegio de México.

MARTínez TORNER, Eduardo, (1986 [1920]). Cancionero musical de la lírica popular asturiana Madrid; repr. Oviedo: Instituto de Estudios Asturianos. 
MARTÍNEZ TORNER, Eduardo (1966): Líric hispánica: relaciones entre lo popular y lo culto, La Lupa y el Escalpelo, 5, Madrid, Castalia.

MASERA, Mariana, (1995): Symbolism and some other aspects of traditional Hispanic lyrics: a comparative study of late medieval lyric and modern popular song, London, Queen Mary, University of London.

MASERA, Mariana (1998): «Tradición oral y escrita en el Cancionero musical de Palacio: el símbolo del cabello como atributo erótico de la belleza femenina». En Cancionero Studies in Honour of Ian Macpherson, ed. Alan Deyermond, 160-71. London: Papers of the Medieval Hispanic Research Seminar.

MASERA, Mariana (1999): «Que non sé filar, ni aspar, ni devanar»: erotismo y trabajo femenino en el Cancionero Hispánico Medieval. En Discursos y representaciones en la Edad Media. Actas de las VI Jornadas Medievales, eds. Company Concepción, González Aurelio y von der Walde Moheno Lillian, México, UNAM-El Colegio de México, pp. 215-231.

MASERA, Mariana (2001a): Canciones tradicionales, enigmas y canciones de brujas en un manuscrito novohispano del siglo XVII. En Lyra Minima Oral. Los géneros breves en la poesía tradicional, eds. Alvar Carlos, Castillo Cristina, Masera Mariana y Pedrosa José Manuel, España, Universidad de Alcalá, pp. 169-77.

MASERA, Mariana (2001): «Que no puedo dormir sola, non»: La voz femenina en la antigua lírica popular hispánica, Barcelona, Azul.

MASERA, Mariana (2004): «La fijación de símbolos en el cancionero tradicional mexicano». Revista de Literaturas Populares, IV-1, pp. 134-156.

MASERA, Mariana (2005): «Los recursos de la copla: paralelismo y simbolismo», La copla en México, González Aurelio (ed.), México, El Colegio de México, pp. 189203. DOI: https://doi.org/10.2307/j.ctvhn07z8.14

MASERA, Mariana (2014): Bailar, saltar y brincar: apuntes sobre el cancionero tradicional hispánico, Colección Ediciones especiales, Nueva Edición, México, IIF, Centro de Poética, UNAM.

MASERA, Mariana y CARRANZA, Claudia (eds.) (2016): Folklore y literatura panhispánica. Lyra Minima I, México, ENES Morelia, UNAM.

DOI: https://doi.org/10.22201/enes.9786070275876e.2016

MÉNDEZ FERRÍn, X. L., ed., (1966): O cancioneiro de Pero Meogo, Vigo, Galaxia.

MENÉNDEZ PIDAL, Ramón (1960): «La primitiva lírica europea. Estado actual del problema», Revista de Filología Española, XLIII-3-4, pp. 279-354. DOI: https://doi.org/10.3989/rfe.1960.v43.i3/4.1016

Morales Blouin, Egla (1981): El ciervo y la fuente: mito y folklore del agua en la lírica tradicional, Potomac, MD, Studia Humanitatis.

Mourinho, Antonio Maria (ed.) (1984): Cancioneiro tradicional e danças populares mirandesas, Bragança, Escolati.

Olinger, Paula (1985): Images of Transformation in Traditional Hispanic Poetry, Newark, DE: Juan de la Cuesta.

Pedrosa, José Manuel (1995): «Poesía trovadoresca de inspiración popular en el siglo XIII: Joan Airas de Santiago, Cielo d'Alcamo y el tópico folclórico románico de El viajero enamorado» en Juan Salvador Paredes Núñez (coord.), Medioevo y literatura: actas el $V$ Congreso de la Asociación Hispánica de Literatura Medieval, vol. 4, pp. 17-28.

PedrosA, José Manuel (1997): «"La flor en la cama”: simbolismo y ritual en un epitalamio sefardí de Marruecos», en Andrew M. Beresford (coord.), «Quien 
hubiese tal ventura»: Medieval Hispanic Studies in Honour of Alan Deyermond, pp. 379-386.

Pedrosa, José Manuel (2002a): «Cuando paso por tu puerta... análisis comparatista de un poema de Miguel Hernández», Nueva Revista de Filología Hispánica, 50-1, pp. 203-216. DOI: https://doi.org/10.24201/nrfh.v50i1.2536

Pedrosa, José Manuel (2002b): Diccionario filológico de literatura medieval española textos y transmisión, en José Luis Mejías y Carlos Alvar (dir.), Madrid, Castalia.

PEDrosA, José Manuel (2005a): «Mujeres en la ventana: alegorías del cuerpo, alegorías del alma», en Rebeca Sanmartín Bastida y Rosa Vidal (coord.), La metamorfosis de la alegoría: discurso y sociedad en la Península Ibérica desde la Edad Media hasta la Edad Contemporánea, pp. 331-348.

DOI: https://doi.org/10.31819/9783964565457-019

Pedrosa, José Manuel (2005b): «El pozo como símbolo erótico: del Libro de buen amor y Góngora a La Regenta y Miguel Hernández», en Pedro M. Piñero (coord.) Dejar hablar a los textos: Homenaje a Francisco Villanueva, pp. 1375-1396.

PEDROSA, José Manuel (2006a): «"La guirnalda de rosas”: tradición y simbolismo en un romance español y sefardí», Miscelánea de estudios árabes y hebraicos. Sección de hebreo, . $^{\circ}$ 55, pp. 191-207.

Pedrosa, José Manuel (2006b): «Arrojar frutos, piedras, amores: entre la canción y el rito», Revista de Literaturas populares, 6-1, pp. 96-127.

Pedrosa, José Manuel (2006c): «Mirra en su árbol, Delgadina en su torre, la mujer del pez en su pozo: el simbolismo "arriba / abajo" en los relatos de incesto», Revista de folklore, . $^{\circ} 312$, pp. 183-194.

PedrosA, José Manuel (2007): «Símbolos del cuento y complementos del vestido...», en Rafael Beltrán (ed), Folklore. Litreratura e indumentaria, Madrid, Ministerio Cultura. Museo del Traje. Centro de Investigación del Patrimonio Etnológico.

Pedrosa, José Manuel (2009): ““Con que te lavas la cara...”: redondillas cortesanas y cuartetas folklóricas», Revista de Folklore, n. ${ }^{\circ} 339$, pp. 98-107.

Pedrosa, José Manuel (2011): «De plumas, tinteros y otros útiles eróticos: la cultura de la voz contra la cultura de la letra», Studia Zamorensia, n. ${ }^{\circ} 10$, pp. 31-66.

Pedrosa, José Manuel (2012.) “"Cuando éramos judíos..." / "Cuando yo en ca de mi padre...": una fórmula lírica de Gil Vicente a un epitalamio sefardí», $e$ Humanista: Journal of Iberian Studies, 20, pp. 239-262.

PedrosA, José Manuel, (2013a): «Los zapatos rotos del Lazarillo de Tormes», Analecta Malacitana, 36 (1-2): pp. 71-100.

Pedrosa, José Manuel (2013b): «Que ni poso en ramo verde ni en prado que tenga flor: romance, mito y metáfora en "Fontefrida"», Edad de Oro, 32, pp. 223-280.

Pedrosa, José Manuel (2013c): «Casas, tejados, amores, canciones: arquitecturas alegóricas del eros femenino», María Jesús Zamora Calvo (ed), La mujer ante el espejo estudios corporales, pp. 203-262.

PedrosA, José Manuel (2014): «"La media noche es pasada, / y no viene": avatares de una canción, entre La Celestina y Alejo Carpentier», Celestinesca, 38, pp. 85-112.

PedrosA, José Manuel (2016): «Poesía lírica castellana tradicional», Fernando Gómez (coord.), Historia de la métrica medieval, pp. 303-352.

Pedrosa, José Manuel (2018): El convite en el palacio de Eros: metáfora, ironía, fórmula y posesión, Madrid, Mitáforas. 
PATCH, Howard Rollin (1956): El otro mundo en la literatura medieval, Jorge Campos (trans.), con apéndice «La visión de trasmundo en las literaturas hispánicas», María Rosa Lida de Malkiel, México, Fondo de Cultura Económica.

PiÑERo RAMíreZ, Pedro M. (2010): La niña y el mar: Formas, temas y motivos tradicionales en el cancionero hispánico moderno, Editorial Iberoamericana. DOI: https://doi.org/10.31819/9783964566362

PiÑERo RAMÍREZ, Pedro M. (2015): De romances varios. Metáforas líricas, valores simbólicos y motivos narrativos, Sevilla, Universidad de Sevilla.

RECKERT, Stephen (1970): Lyra minima: Structure and Symbol in Iberian Traditional Verse, London, King's College.

RECKERT, Stephen (1993): Beyond Chrysanthemums: Perspectives on Poetry East and West, Oxford, Clarendon Press.

RECKERT, Stephen (2001): Más allá de las neblinas de noviembre, Madrid, Gredos.

RECKERT, Stephen y Helder, MACEDO (1976): Do cancioneiro de amigo, Documenta Poética, 3, Lisboa: Assírio \& Alvim.

Rielo Carballo, Isaac (ed.) (1980): Cancioneiro da Terra Cha (Pol), Cuadernos del Seminario de Estudios Cerámicos de Sargadelos, 35, La Coruña, Ediciós do Castro.

Ricoeur, Paul, 1995. Teoría de la interpretación. Discurso y excedente de sentido, México, Siglo XXI.

RICO VerEA, Manuel (ed.) (1989): Cancioneiro popular das Terras do Tamarela, Vigo, Galaxia.

SCHINDLER, Kurt (ed.) (1941): Folk Music and Poetry of Spain and Portugal, New York, Lancaster Press.

SoKolov, Y. M. (1971): Russian Folklore, Detroit, Folklore Associates.

THOMPSON, Stith (1955-58): Motif-Index of Folk-Literature: A Classification of Narrative Elements in Folktales, Ballads, Myths, Fables, Medieval Romances, Exempla, Fabliaux, Jest-Books, and Local Legends, 2nd edn, 6 vols, Bloomington, Indiana UP, Copenhagen, Rosenkilde \& Bagger.

TORNER, Eduardo M[artínez] (ed.) (1920): Cancionero musical de la lírica popular asturiana, Madrid, repr. Oviedo, Instituto de Estudios Asturianos.

VAn GenneP, Arnold, 2004. The Rites of Passage. Oxford, New York: Routledge.

WimBerly, Lowry Charles (1928): Ghosts, Magic, Witches, Fairies, the Otherworld: Folklore in the English \& Scottish Ballads, Chicago, University Press.

Wunenburger, Jean Jacques (2008): Antropología del imaginario, Buenos Aires, Del Sol.

\section{SITIOS WEB}

O cantinho das Crianças. URL:

$<$ https://sites.google.com/site/ocantinhodasbrincadeiras/cancoes/as-pombinhasda-catrina-1Consulta>

Fecha de recepción: 2 de septiembre de 2019

Fecha de aceptación: 2 de septiembre de 2019

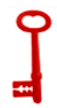

